\title{
A comparative study of atmospheric Maxwell current and electric field from a low latitude station, Tirunelveli
}

\author{
C. Panneerselvam ${ }^{1}$, K. U. Nair ${ }^{1}$, K. Jeeva ${ }^{1}$, C. Selvaraj ${ }^{1}$, S. Gurubaran ${ }^{1}$, and R. Rajaram ${ }^{1,2}$ \\ ${ }^{1}$ Equatorial Geophysical Research Laboratory, Indian Institute of Geomagnetism, Krishnapuram, Tirunelveli 627 011, India \\ ${ }^{2}$ Indian Institute of Geomagnetism, New Panvel, Navi Mumbai 410 218, India
}

(Received June 9, 2003; Revised October 22, 2003; Accepted October 22, 2003)

\begin{abstract}
Simultaneous measurements of atmospheric Maxwell current and electric field, using horizontal long wire antenna and passive horizontal wire antenna system at $1 \mathrm{~m}$ above the Earth's surface, were carried out at Tirunelveli $\left(8.7^{\circ} \mathrm{N}, 77.8^{\circ} \mathrm{E}\right)$, India, during January/February 2002 . The objectives of the present work have been to understand the nature of the measured atmospheric electrical parameters and explore the possibility of detecting the signature associated with the global thunderstorm activity. As the measurements indicate, the atmospheric electrical parameters at Tirunelveli are severely masked by the locally induced current components during disturbed weather conditions, for example, severe convective activity. During the selected fair weather conditions, the hourly averaged diurnal variation curves of Maxwell current and electric field are characterized by two peaks: The first peak is the local "sunrise effect" and the second peak occurs at times close to 1900 UT, the time of maximum global thunderstorm activity as noted in the famous "Carniege curve". The correlation coefficient between the measured Maxwell current and electric field has a high value (more than 0.8) for all the fair weather days. These results support our view that this site is free from local pollution during the fair weather conditions and is suitable for long-term measurements of atmospheric electrical parameters.
\end{abstract}

Key words: Air-earth current, Maxwell current, electric field, fairweather day, sunrise effect, global electric circuit.

\section{Introduction}

The study of global electric circuit (GEC) provides a platform for understanding the solar-terrestrial relationship and offers possibilities for exploring one of the traditional scientific problems for the last several centuries, namely, that of associating changes in lower atmospheric weather with the solar output (Herman and Goldberg, 1978). In spite of several mechanisms having been proposed there still lie uncertainties in identifying the actual physical processes that govern the envisioned relationship between the sun and the changes in weather.

Continuous measurements of atmospheric electrical parameters, namely, the vertical electric field, the conductivity and the air-earth current density, that characterize the GEC, are considered useful in any study aiming towards understanding fully the electrical environment of the Earth. Further, since the global circuital path links the lower troposphere, the ionosphere and the magnetosphere, the measurements of atmospheric electrical parameters will be handy in any integrated approach that involve all these regions. Longterm measurements would be considered useful for addressing some of the problems associated with global change.

Many attempts have been made in the past to identify global signatures in the measured atmospheric electrical parameters that are expected to confirm the global circuit concept established by Wilson (1925). The site of measurements needs to be free of atmospheric aerosols and convec-

Copy right (C) The Society of Geomagnetism and Earth, Planetary and Space Science (SGEPSS); The Seismological Society of Japan; The Volcanological Society of Japan; The Geodetic Society of Japan; The Japanese Society for Planetary Sciences. tive activity that otherwise would obscure the weak signatures representing the global thunderstorm activity (Israel, 1973). Adlerman and Williams (1996) used data on air-earth current density at Mauna Loa in Hawaii, a site free of pollution and that remains above the inversion layer most of the time. Ruling out earlier measurements from different stations as possibly due to local processes, Adlerman and Williams (1996) could detect the evening peak (at around 1900 UT) in the UT variation of the measured current density over Mauna Loa Observatory. Apart from the global UT variation, land stations also exhibit local time variation typical of their locations. The most universal of these is the socalled sunrise effect. Muir $(1975,1977)$ tried to explain this feature on the basis of the sunrise effect at the height of electrosphere leading to build up of a potential through dynamic motion associated with tides.

In the present work Maxwell current and electric field measurements made from a low latitude station near the southern tip of the Indian peninsula, are made use of for examining the possibility of detecting global signatures in the tropical Indian zone and evaluating the contributions of local processes in the variabilities of tropical atmospheric electrical parameters. A variety of scientific experiments are conducted at this remote site situated close to the magnetic equator. We are also operating an automatic weather station at this location for monitoring the wet and dry temperatures, wind speed, wind direction and rainfall at a sampling interval of one minute. 


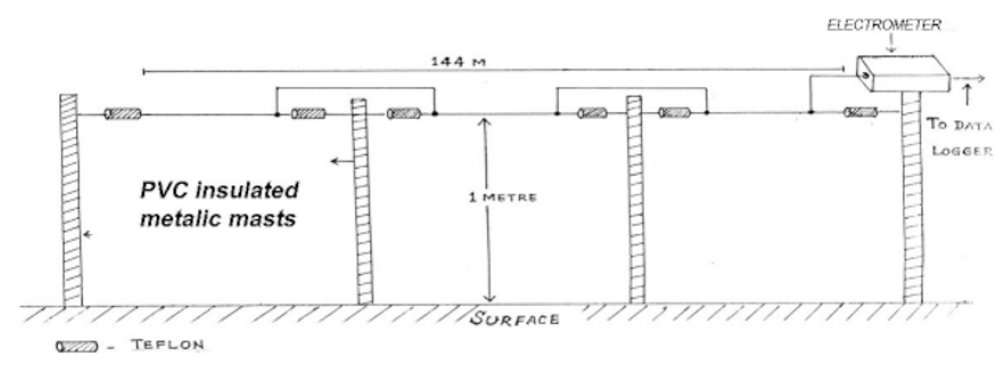

Fig. 1. Sketch of the Maxwell current experiment.

\section{Maxwell current electrometer (AD549) calibrated at NPL}

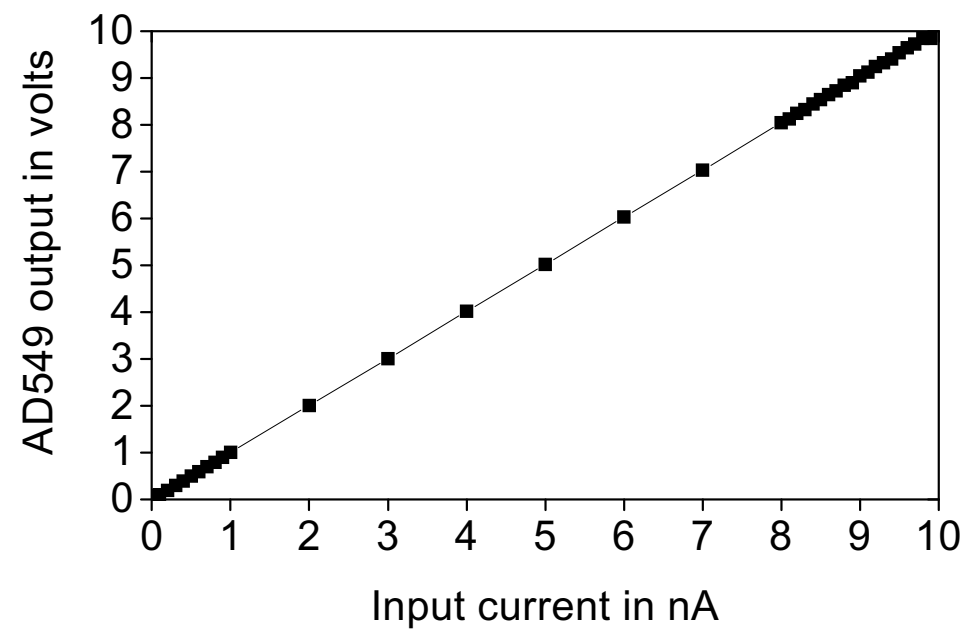

Fig. 2. Electrometer (AD 549) calibration curve.

\section{Site Description}

The experimental site ( $35 \mathrm{~m}$ above mean sea level) is more than $12 \mathrm{~km}$ from the twin towns of Tirunelveli and Palayamkottai towards the southeast. The site is about 35 $\mathrm{km}$ from the Bay of Bengal and the nearest hills of Western Ghats are at distances of $\sim 45 \mathrm{~km}$ towards the west. The crustal part of the earth over the site is fixed on solid rocks, and hence does not support vegetation. The landscape is nearly flat and there are no trees in the vicinity of the sensors. The experimental site receives rainfall normally during the months of October and November when the northeast monsoon is active. Occasional rains occur during the summer when the southwest monsoon prevails in the Indian subcontinent. Scanty rainfall over most of the year in this region permits a large number of atmospheric electricity measurements to be made. Being in the tropics, this region is under the influence of convection that is expected to be severe during the late spring and early summer months (April-June).

\section{Experimental Technique}

There are several methods available for the measurements of atmospheric electrical parameters. An important and the most informative parameter of the global electric circuit is the Maxwell current (Ruhnke, 1965). Ground-based measurements are valuable because they provide continuous long-term recordings. The common ground-based sensors used for current measurements are Wilson plate, the horizontal long-wire antenna and the spherical shell in the form of two hollow hemispheres. The long-wire antenna is a good alternative since it allows for the suppression of local disturbances by averaging the vertical current over a large area (Tammet et al., 1996). By this technique, the contributions from the convection current can be made minimum. The horizontal long wire antenna, if placed in the atmosphere, will closely follow the electrical current variations of the atmosphere by collecting incoming charges from the atmosphere after the initial net charge on the antenna leaks off. When the antenna is shorted to the ground through a resistor, it will pick up a certain amount of current proportional to the Maxwell current.

In the present work we use a long wire antenna of $144 \mathrm{~m}$ in length and $3 \mathrm{~mm}$ in diameter. The sensor is supported 1 $m$ above the ground by means of masts that are electrically separated by teflon rods as shown in Fig. 1. The sensor is connected to the electrometer (Model AD549) that has high input impedance of the order of $10^{9} \Omega$ and permits extremely low input bias current $\left(10^{-14} \mathrm{~A}\right)$. The electrometer converts the current into voltage. The electrometer measures the current in the range of a few picoamperes (pA) to a few nanoamperes $(\mathrm{nA})$ with the high feedback resistance $\left(5 \times 10^{9} \Omega\right)$ chosen for this experimental setup. A unity gain operational amplifier (LM308) is connected to the electrometer output 


\section{Sketch diagram of Passive antenna system}

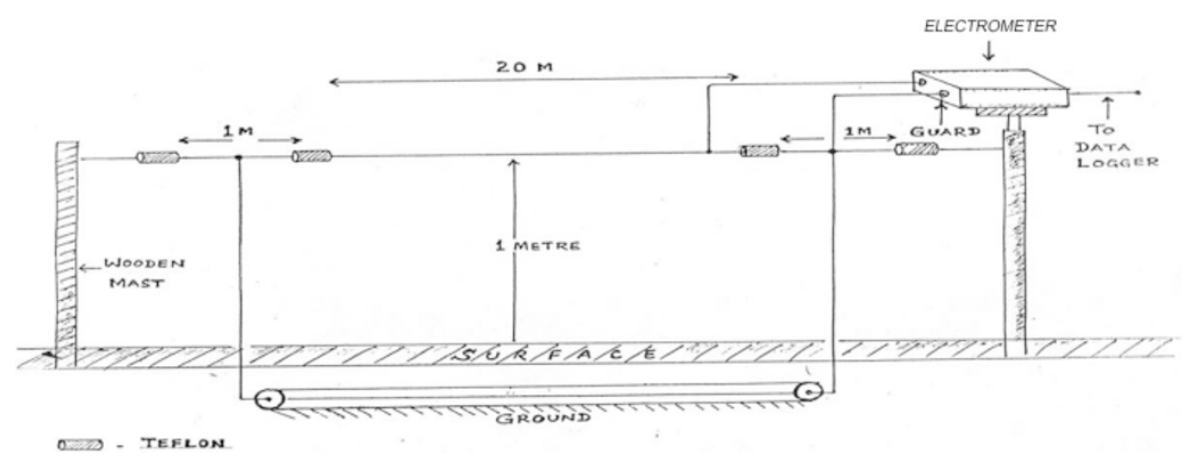

Fig. 3. Sketch of the passive antenna system.

(a)

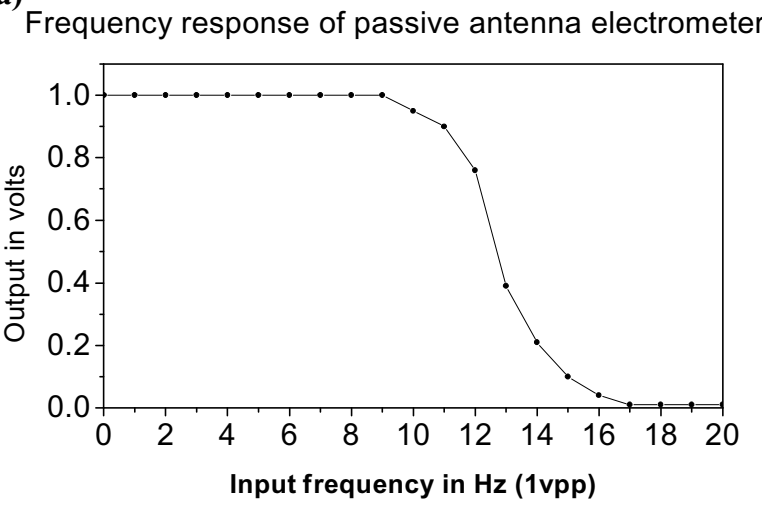

(b)

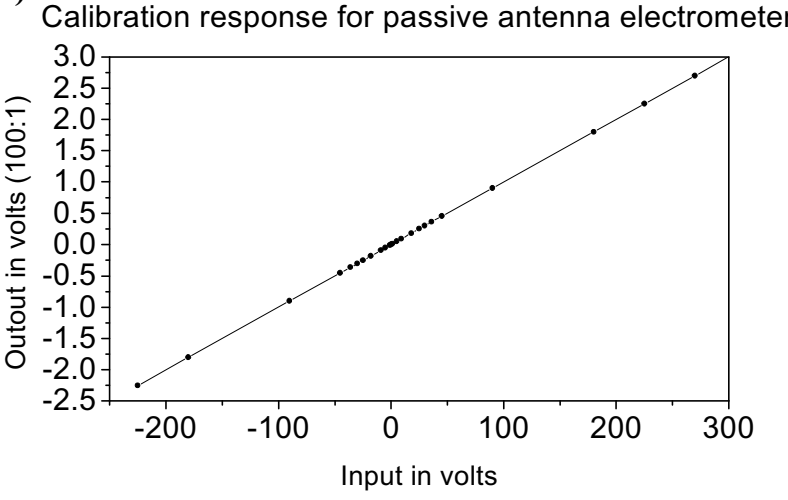

Fig. 4. (a) Passive antenna frequency response curve. (b) Passive antenna input output voltage response curve.

signal. The output signals are filtered by a low pass filter with a cut-off period of 1 second $(3 \mathrm{~dB})$ at the input of an analog-to-digital converter (ADC) that is $100 \mathrm{~m}$ away from the preamplifier. The filtered signal is fed to the 12 bit ADC (AD574) with $2.44 \mathrm{mV}$ resolution which is mounted inside the personal computer (PC). The PC records the signal at a sampling interval of one second. The hourly averaging of the data samples carried out during the analysis stage further eliminates any short-period variations in the measured current.

The electrometers were calibrated for their performance at the National Physical Laboratory, New Delhi, India. The calibration curve obtained from this exercise is shown in Fig. 2. A simple linearity between the input current source and the electrometer output was observed as noticed in Fig. 2.

The effective area of the present experimental setup using the Kasemir-Ruhnke model (Kasemir and Ruhnke, 1959) is $158.12 \mathrm{~m}^{2}$ calculated from the formula $(S=h C / \epsilon), \epsilon$ being the dielectric constant of air, $C$ is the capacitance of the antenna and $h$ is the height of the antenna above ground. As realized in the recent past, this effective area works well for the displacement current whereas the current flow lines representing the conduction current are not expected to match the electric field lines in the presence of inhomogeneities induced by space charges and convection currents. The static effective area proposed by Tammet et al. (1996), which is appropriate for determining conduction current density using long-wire antenna, involves polar conductivity and electric potential. Experimental verification for this model is yet to be forthcoming. For the present work, we express the longwire antenna measurements in current units rather than current density units.

The atmospheric electric field has been measured with a horizontal passive wire antenna of $20 \mathrm{~m}$ in length and $3 \mathrm{~mm}$ in diameter made of tinned copper. The sensor is supported $1 \mathrm{~m}$ above the ground by means of masts. At each end there are porcelain egg insulators, and a PTFE (Poly Tetra Flouro Ethylene) or teflon insulator under steady compression at the masts shown in Fig. 3. The insulators are regularly cleaned with isopropanol. A guard potential, which is close to the potential on the wire, is applied to the support wires at each end. This is to minimize the leakage through the insulators, which would occur if the support were merely grounded. As a precaution against the guard potential influencing the potential sensed by the antenna, the parallel cable that carries the guard signal to the far end of the antenna has an earthed screen. The antenna makes contact with a short wire made of same material as that of the antenna, which is connected to a voltage follower electrometer (LMC 6042) with the unity gain that permits ultra low input bias current of nearly 1 fA. The frequency response of the electrometer is shown in Fig. 4(a). The amplified signals are filtered by the low pass filter at the input of ADC, which is $100 \mathrm{~m}$ away from the preamplifier. The filtered signal is fed to the 12 bit ADC. The response of the passive antenna electrometer to specific input voltages is shown in Fig. 4(b). 

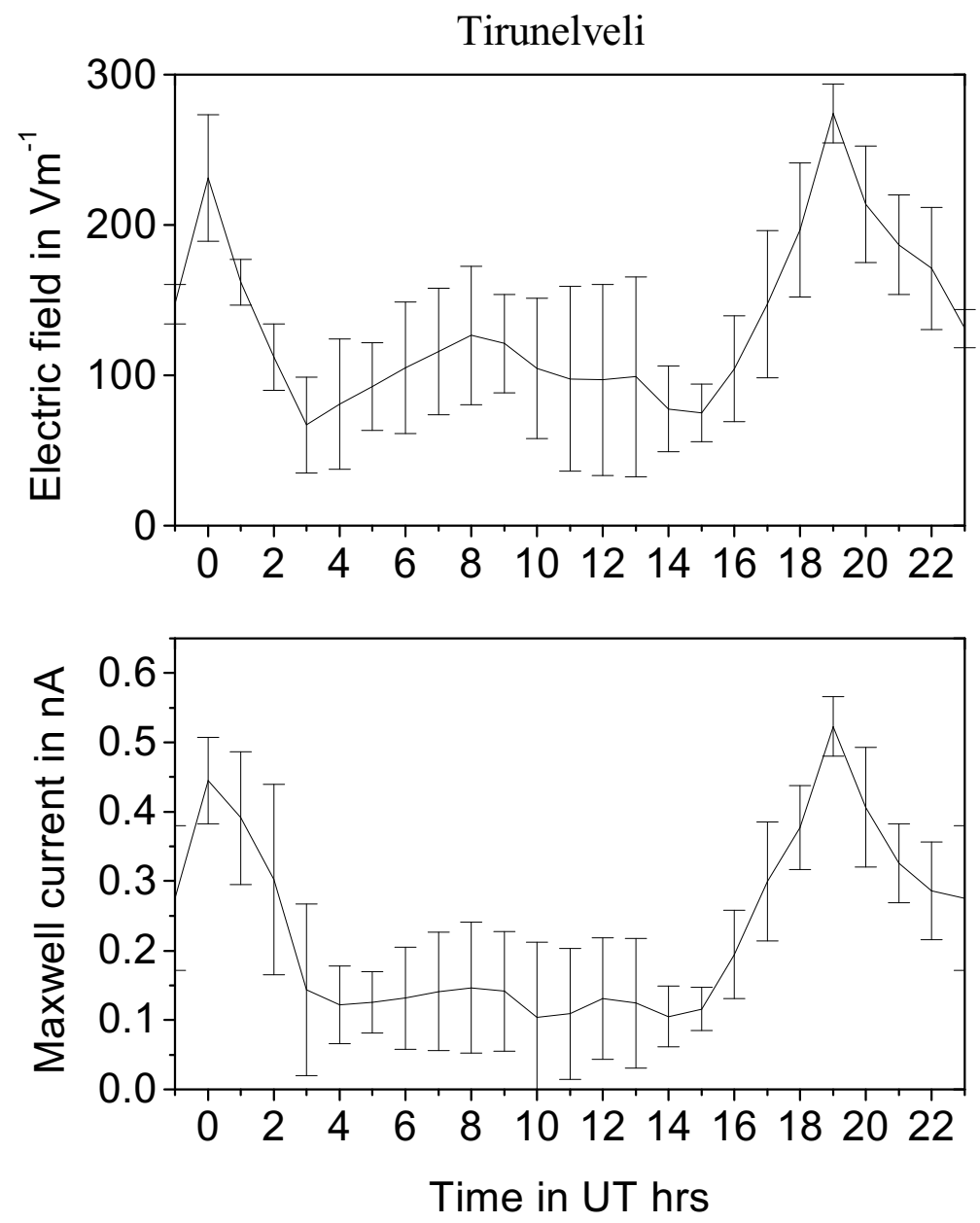

Fig. 5. Diurnal variations of Maxwell current and electric field at Tirunelveli averaged over 8 fair weather days during January/February 2002.

\section{Results and Discussion}

The hourly averaging procedure is most suited for the identification of the signatures of global electric circuit. Since the charge generated by a thunderstorm somewhere on the globe is distributed in the equalizing layer (ionosphere) within 10-15 minutes, mean values of measurements over at least 30 minute duration would be required if the global thunderstorm activity is to be adequately represented (Reiter, 1992). One-hour averages are considered in the present work for examining the diurnal variation in the measured parameters. We define a fair weather day when there is no rainfall at the measuring site, high clouds less than 3 octas throughout the day, and wind speed less than or equal to $10 \mathrm{~ms}^{-1}$.

The diurnal variations of the electric field $(E=V / h$ where $V$ is potential and $h$ is in meters) and Maxwell current (I) averaged for the selected fair weather days during January/February 2002 are depicted in Fig. 5. In this figure we have included average values corresponding to one hour before 0000 UT to show the sunrise effect that occurs at $\sim 0000$ UT. The diurnal variations show a local morning and a local evening maximum feature during this period. There are peaks at 0000 UT 1900 UT. In order to examine the sunrise effect in more detail we have used the one-minute averaged data that are shown in Fig. 6. These data are plotted in Indian Standard Time (IST) which is 5.5 hours ahead of UT. It is seen that $E$ and $I$ begin to rise 30 minutes before ground sunrise (sunrise time at Tirunelveli is 0631 IST (the local time is 18.8 minutes behind IST) for this month). The increase in the measured parameters before ground sunrise is perhaps related to the process at some height in the atmosphere that will see an earlier sunrise. A time difference of $\sim 30$ min between the rise time of the electrical parameters and the ground sunrise time reveals that such height could be somewhere in the region between stratopause and the ionosphere. The maximum that occurred at 1900 UT in Figs. 5 and 6 is believed to be associated with the global thunderstorm activity.

The correlation between Maxwell current and the electric field variations are shown in Fig. 7. The correlation coefficient for these measured parameters has a high value (more than 0.8) during the fairweather days. From the slope of the curve the conductivity was calculated and its value is $1.0 \times 10^{-14} \mathrm{~S} / \mathrm{m}$.

The global UT variation in atmospheric electrical parameters is expected to show a maximum at 1900 UT and a minimum at 0300 UT. The present data on electric field and current do show a maximum at 1900 UT. The local sunrise effect obscures global signature at least during certain other times. The other local processes that contaminate the global signal are due to dew and mist that may be present in the morning hours on some days. The space charges that exist at the time of evaporation from dew or mist may contribute 

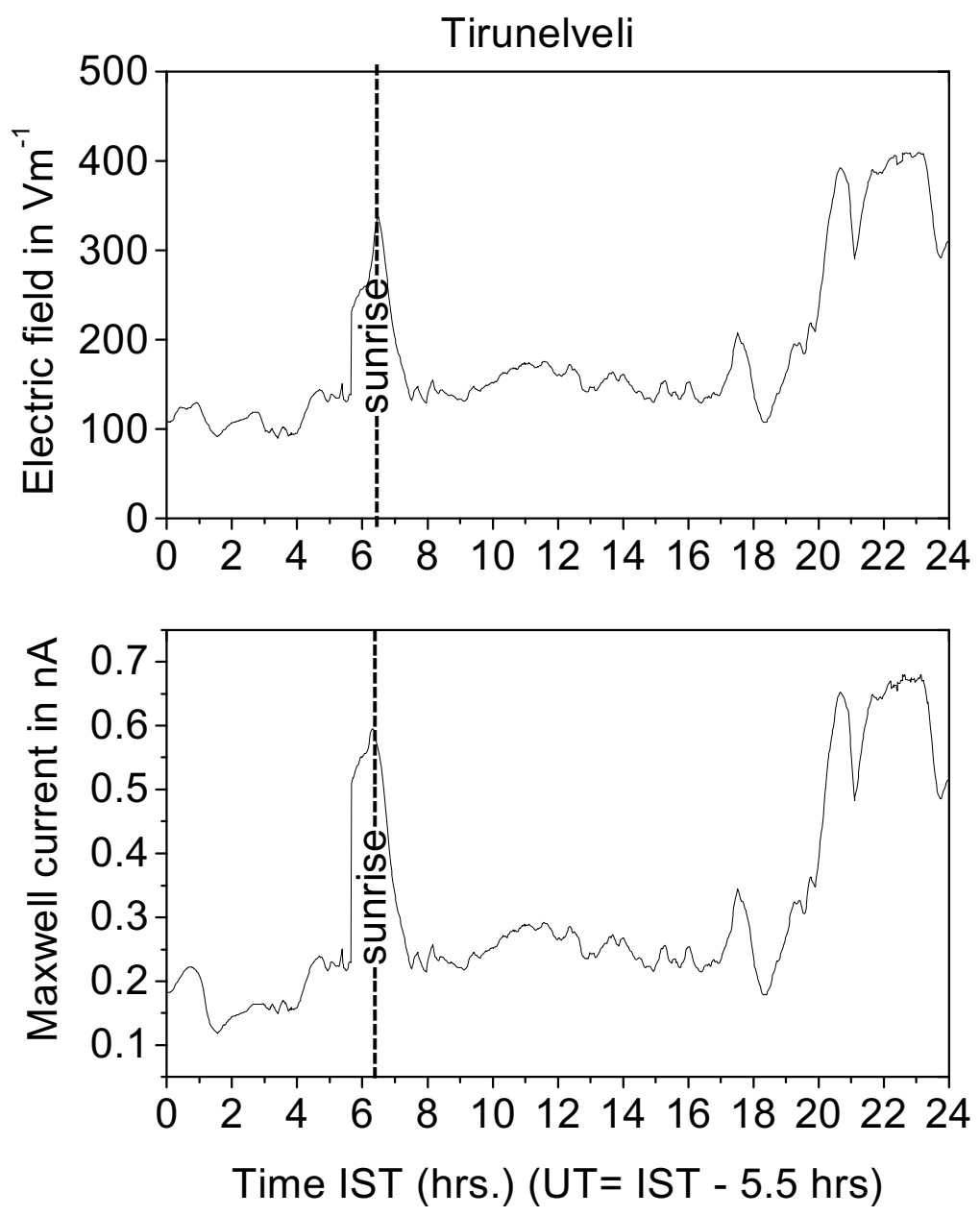

Fig. 6. Diurnal variations of Maxwell current and electric field (one-minute data) on 20 January 2002.

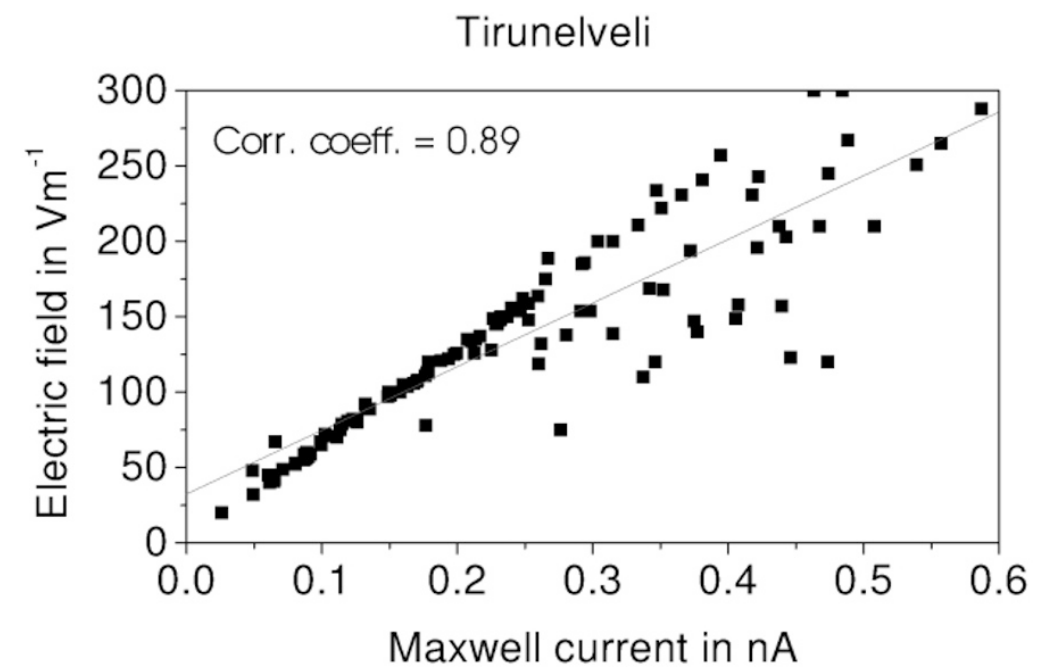

Fig. 7. Maxwell current Vs electric field at Tirunelveli for 8 fair weather days during January/February 2002.

to the observed variations in electrical parameters (Karasnogorskaya and Pokhmelnik, 1983, for example).

The variations observed in $I$ and $E$ at this low latitude station differ markedly from those reported from other low and middle latitudes (Israel, 1973; Burke and Few, 1978; Reiter, 1985; Adlerman and Williams, 1996). Israel (1973) found no characteristic fundamental behavior among the measure- ments from ten continental stations. This can be realized if one considers the relationship between the field intensity $(E)$, current $(I)$, and column resistivity $(R)$, given by $E=w V / R=w . I$, where $w$ is the resistivity at the observation point, $V$ is the total potential difference between the earth's surface and the atmospheric electric equalization layer, and $I$ is the current. Though the field intensity de- 

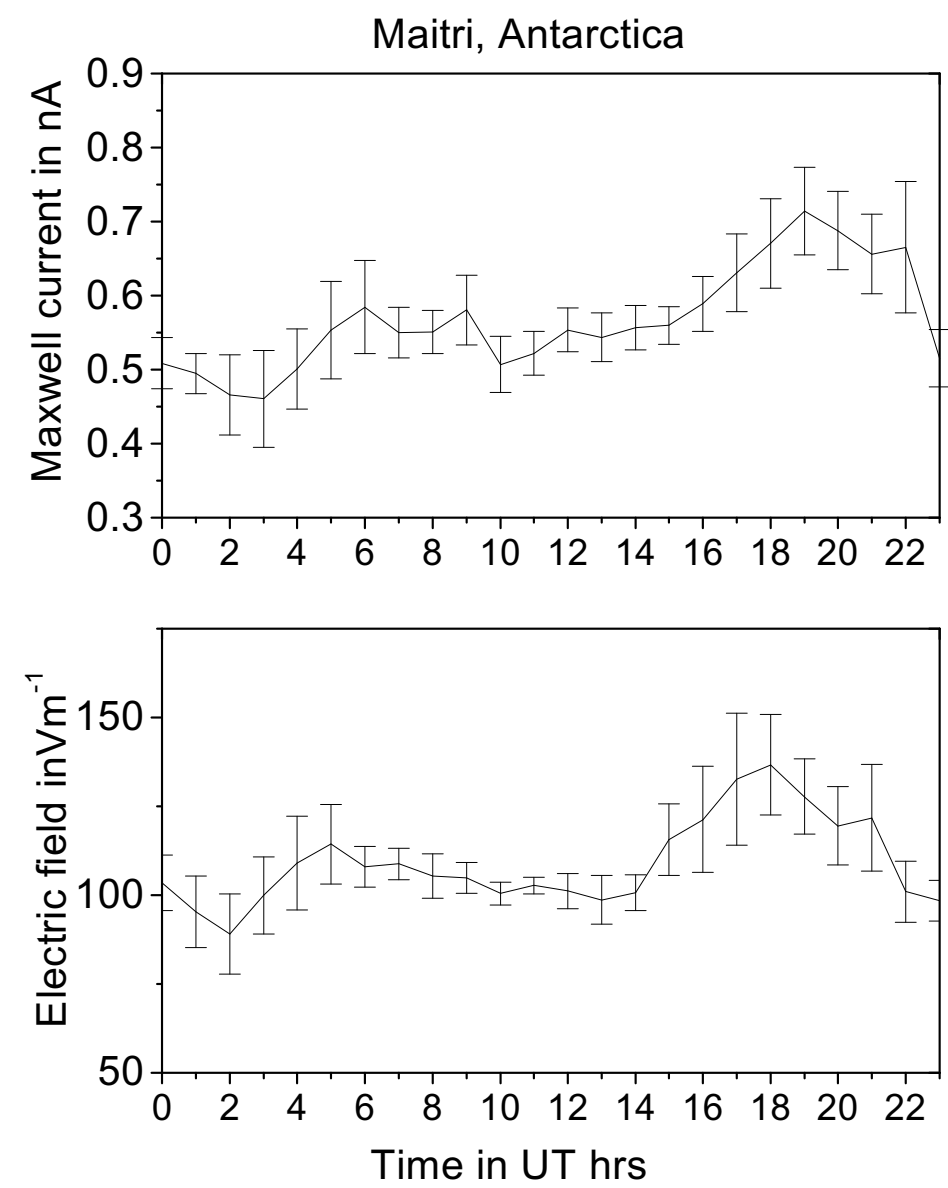

Fig. 8. Diurnal variations of Maxwell current and vertical electric field at Maitri, Antarctica averaged for 10 fair weather days during January/February 2001.Diurnal variations of Maxwell current density and vertical electric field at Maitri, Antarctica averaged for 10 fair weather days during January/February 2001.

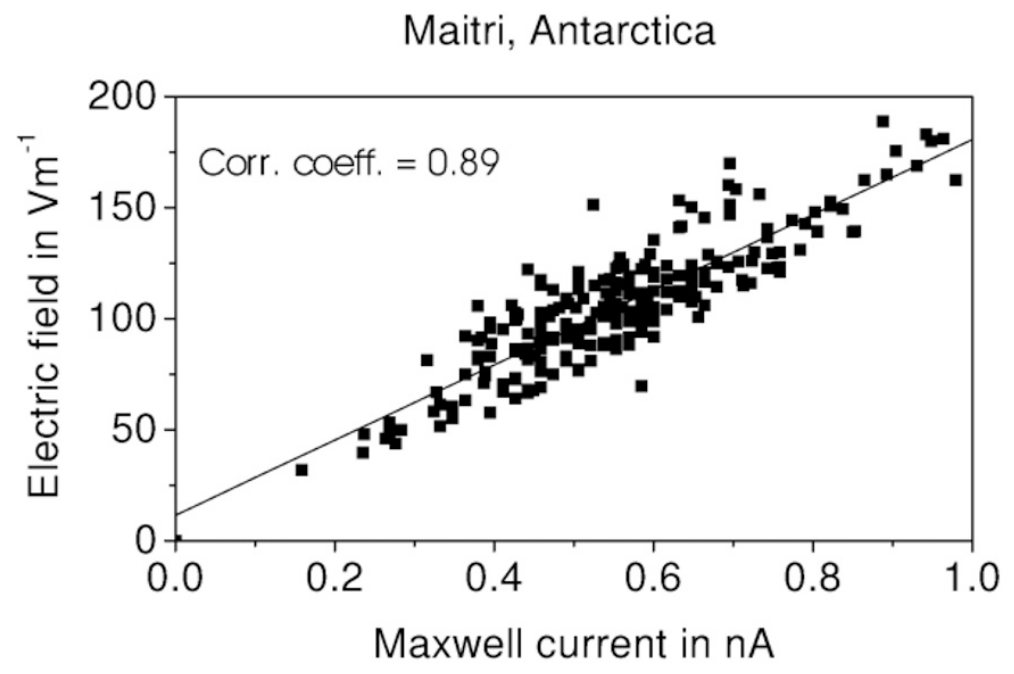

Fig. 9. Scatter plot for Maxwell current and electric field at Maitri, Antarctica, for ten fair weather days during January/February 2001.

pends strongly on the meteorological processes through its dependence on the local resistivity $w$, the current, given by $I=V / R$, is less sensitive to local changes in conductivity. However, changes in the columnar resistance, induced by the atmospheric suspension content and its vertical transport, may be expected to dominate the vertical current and its variations. Thus the behavior of I depends on whether the percentage changes in $V$ or $R$ dominate. Over the continental stations one can expect that the changes associated with $R$ are larger than those associated with $V$ (Israel, 1973). Gringel et al. (1986) showed that the first two km of the atmosphere contribute about 50 percent to the total columnar resistance and the first $13 \mathrm{~km}$ about 95 percent. With observations conducted at Weissnau, Germany, Gringel et al. 
(1986) measured a variation in $R$ of about 30 percent, and attributed the variation to a changing ionization near ground and by varying aerosol concentrations in the lower troposphere. Muir $(1975,1977)$ tried to explain it on the basis of sunrise effect at the height of electrosphere leading to build up of a potential through dynamic motion associated with tides.

We have also been conducting Maxwell current, Gerdien conductivity meter and field mill experiment at the Indian Antarctic station, Maitri $\left(70.8^{\circ} \mathrm{S}, 11.8^{\circ} \mathrm{E}\right)$. The diurnal variation of the measured vertical electric field and Maxwell current averaged over 10 fair weather days during January/February 2001 shows single maxima at about 1900 UT and minimum near about 0300 UT and is shown in Fig. 8. The data from Antarctica show that the sunrise effect is not present at this station. Since the observation is made during the austral summer there is no any significant change in the sunlight as the sun is visible round the clock. The Maxwell current is plotted against the electric field in Fig. 9 and as noted the correlation coefficient for these measured parameters has a high value (more than 0.8 ) during these fair weather days. The estimated atmospheric conductivity is $2.0 \times 10^{-14} \mathrm{~S} / \mathrm{m}$.

\section{Conclusion}

The long-wire antenna and passive antenna employed in the present work demonstrate to provide useful data on the Maxwell current and potential from a tropical pollution free site. The morning sunrise enhancement observed on the fair weather days is a local effect whereas the 1900 UT maximum in the measured electrical parameters are attributed to the global thunderstorm activity that is expected to peak at these hours. Measurements from the southern continent, Antarctica, with a similar experimental setup confirm our analysis of local and global effects in the data obtained from the continental site. These results support our view that this site is free from local pollution and is suitable for long-term measurements of atmospheric electrical parameters. The Antarctic data have shown the capability of providing high quality and high resolution data for monitoring the global electric circuit (Panneerselvam et al., 2001), to study the long-term climate and short period weather coupling processes. With continuous measurements of atmospheric electrical parameters and the geomagnetic field variations there is scope for addressing to the problems related to the modulation of global electric circuit by upper atmospheric effects.

During the course of this investigation pre-sunrise effect is most noticeable. Muir $(1975,1977)$ has suggested that the processes of ionization in the ionosphere and polarization in the electrosphere at sunrise would result in an increase in the potential of that part of the electrosphere experiencing sunrise. This would be possibly detected as an increase in the atmospheric electrical parameters at the ground. This pre-sunrise effect would be caused by a tidal sunrise effect at the height of the electrosphere (where sunrise occurs earlier than sunrise at the ground). Further studies are needed to be sure of the cause of the pre-sunrise effect.

Acknowledgments. The authors gratefully acknowledge the valuable remarks of the referees, which helped in making improvements on the original version. The authors thank Prof. B. N. Raina for very many useful discussions. The Gerdien conductivity meter and the field mill were provided by the Indian Institute of Tropical Meteorology, Pune, under a collaborative study. This work is supported by the Department of Science and Technology (DST), Government of India. The logistic support provided by the Department of Ocean Development, Government of India, for conducting a variety of experiments at the Indian Antarctic station, Maitri, is gratefully acknowledged.

\section{References}

Adlerman, E. J. and E. R. Williams, Seasonal variation of the global electric circuit, J. Geophys. Res., 101, 29,679-29,688, 1996.

Burke, H. K. and A. A. Few, Direct measurements of the atmospheric conduction current, J. Geophys. Res., 83, 3093-3098, 1978.

Gringel, W., J. M. Rosen, and D. J. Hofmann, Electrical Structure from 0 to 30 kilometres, in The Earth's Electrical Environment, edited by E. P. Krider and R. G. Roble, pp. 149-165, Nat. Acad. Press, Washington, D.C, 1986.

Herman, J. R. and R. A. Goldberg, In Sun, Weather and Climate, Scientific and Technical Information Branch, National Aeronautics and Space Administration, Washington, D.C, 1978.

Hoppel, W. A., R. V. Anderson, and J. D. J. C. Willett, Atmospheric Electricity in the Planatary Boundary Layer, in Earths Electrical Environment, National Academy Press, Washington D.C, 1986.

Israel, H., Atmospheric Electricity, Vol. II, Israel Programme for Sci. Transl., Jerusalem, 1973.

Karasnogorskaya, N. A. and D. A. Pokhmelnik, On the origin of Variations in the Electric field of the Earth's Atmosphere, Proceedings in Atmospheric Electricity, 79-84, 1983.

Kasemir, H. W. and L. H. Ruhnke, Antenna problems of measurement of the air-Earth current, in Recent advances in Atmospheric Electricity, edited by L. G. Smith, pp. 137-147, Pergamon, New York, 1959.

Muir, M. S., The ionosphere as the source of the atmospheric electric sunrise effect, J. Atmos. Terr. Phys., 37, 553-559, 1975.

Muir, M. S., The potential gradient sunrise effect in atmospheric electricity, J. Atmos. Terr. Phys, 39, 229-233, 1977.

Panneerselvam, C., K. U. Nair, K. Jeeva, S. Gurubaran, R. Rajaram, and G. Rajaram, First results from the measurements of atmospheric Maxwell current at Maitri, Antarctica, Proceedings on Meteorology for Sustainable Development TROPMET 2001, Allied Publishers Pvt. Ltd., Mumbai, 365-368, 2002.

Reiter, R., Fileds, Currents and Aerosols in the Lower Troposphere, published for the division of Atmospheric Sciences, National Science Foundation, Washington, D.C., by Amerind Publishing Co. Pvt. Ltd., New Delhi, 1985.

Reiter, R., Phenomena in Atmospheric and Environmental Electricity, Elsevier, 541 pp., New York, 1992.

Ruhnke, L. H., Area averaging of atmospheric electric currents, J. Geomagn. Geoelectr, 21, 453-462, 1965.

Tammet, H., S. Israelsson, K. Knudsen, and T. J. Tuomi, Effective area of a horizontal long-wire antenna collecting the atmospheric electric vertical current, J. Geophys. Res., 101, 29671-29678, 1996.

Wilson, C. T. R., The electric field of a thundercloud and some of its effects, Proc. Phys. Soc. London, 37, 32d 1925

C. Panneerselvam (e-mail: egrl@sancharnet.in), K. U. Nair, K. Jeeva, C. Selvaraj, S. Gurubaran, and R. Rajaram 